\title{
Fenômenos de Termodinâmica e TransferênCIa de Calor em Sistemas de Aquecimento de Combustível para Partida a Frio de Motores de COMBUSTÃo INTERNA
}

\author{
Arthur V. S. Oliveira ${ }^{1,2}$, Guilherme H. M. Alegre ${ }^{1}$, Rogério G. Santos ${ }^{2}$, \\ Fernando L. Windlin ${ }^{1}$ \\ ${ }^{1}$ Magneti Marelli Sistemas Automotivos, Divisão Powertrain \\ ${ }^{2}$ Universidade Estadual de Campinas, UNICAMP \\ E-mails: arthurvo@fem.unicamp.br, guilherme.alegre@magnetimarelli.com, \\ roger7@fem.unicamp.br, fernando.windlin@magnetimarelli.com
}

\section{RESUMO}

No Brasil, o etanol é um popular combustível alternativo à gasolina, especialmente após 2003, quando veículos Flexfuel foram introduzidos no mercado. No entanto, há complicações durante a partida a frio do motor com etanol, devido à sua baixa pressão de vapor e alto ponto de fulgor. A primeira solução para superar o problema foi injeção de gasolina para partida do motor em baixas temperaturas, utilizando uma linha de combustível própria para este fim. Recentemente, a solução de injeção de combustível aquecido foi adotada no mercado pelas montadoras. Seu projeto envolve conceitos de transferência de calor e termodinâmica que devem ser considerados para projetar os componentes e prever seu desempenho, de forma a aquecer o combustível o mais rápido possível de forma segura. O presente trabalho é uma breve discussão sobre a termodinâmica do aquecimento de combustível e fenômenos de transferência de calor que ocorrem neste processo. Maior atenção é dada à transferência de calor por ebulição, com os resultados experimentais deste fenômeno com etanol e gasolina. Resultados de Fluidodinâmica Computacional (CFD) também são apresentados, mostrando sua capacidade qualitativa de prever o comportamento do aquecimento que auxiliam o desenvolvimento de produtos.

\section{INTRODUÇÃO}

No Brasil, motores de combustão interna movidos a etanol são populares há mais de três décadas. A primeira impulsão do etanol combustível foi em 1975 com a criação do Programa Nacional do Álcool (Pró-Álcool) e em 1979 com a produção de veículos movidos 100\% a etanol hidratado, mesmo tendo o primeiro veículo brasileiro a etanol feito em 1925 [1]. A segunda foi em 2003, com o advento dos veículos Flexfuel [2], onde o consumidor final poderia escolher livremente com qual combustível abastecer (etanol e gasolina), independente da proporção da mistura.

No entanto, como já bastante conhecido pelo setor automotivo, motores movidos a etanol tem bastante dificuldade de partir em baixas temperaturas. Isto ocorre devido à baixa pressão de vapor e ao alto ponto de fulgor do etanol (vide Tabela $1 \mathrm{com}$ algumas propriedades do etanol e da gasolina). Apesar de o Brasil ser um país tropical com temperaturas médias relativamente 
altas, o problema da partida a frio com etanol pode ocorrer em locais com temperaturas abaixo de $15{ }^{\circ} \mathrm{C}$ (comum na região Sudeste e Sul do país).

Tabela 1: Algumas propriedades do Etanol e da Gasolina [3]

\begin{tabular}{|c|c|c|}
\hline Propriedade & Etanol & Gasolina Automotiva \\
\hline Pressão de Vapor & $6.7 \mathrm{kPa} @ 25^{\circ} \mathrm{C}$ & $\begin{array}{c}\text { Reid Vapor Pressure } \\
51 \mathrm{kPa} @ 38^{\circ} \mathrm{C}\end{array}$ \\
\hline Ponto de Fulgor & $12.7^{\circ} \mathrm{C}$ & $-37.7^{\circ} \mathrm{C}$ \\
\hline Temperatura de Autoignição & $365^{\circ} \mathrm{C}$ & $456^{\circ} \mathrm{C}$ \\
\hline
\end{tabular}

A primeira solução para contornar este problema foi injeção de gasolina por um sistema de combustível auxiliar, que é utilizado apenas para a partida do motor quando em baixas temperaturas. Apesar de eficaz, esta é uma solução que desagrada o usuário final, pois precisa se preocupar em abastecer o "tanquinho" auxiliar.

A tecnologia mais recente é a de combustível aquecido durante a partida. Desta forma, elevase a pressão de vapor para, no momento da injeção, melhorar sua atomização [4] [5] e permitir a combustão em baixas temperaturas. Deve-se notar que o aquecimento deste combustível deve ser realizado da forma mais rápida possível, pois, no contrário, o usuário final deverá aguardar o fim do processo para que seja permitida a partida do motor. Esta espera pode lhe causar incômodo e deixa-lo insatisfeito com o produto. Por outro lado, a elevada potência de aquecimento deve ser utilizada corretamente para não danificar componentes da linha de combustível.

Este trabalho apresenta as características gerais dos fenômenos físicos envolvidos nos sistemas de aquecimento de combustível. Na primeira parte, uma breve abordagem é feita no propósito do aquecimento de combustível. Posteriormente, um levantamento embasado nos fenômenos termodinâmicos é realizado, seguido por detalhes nos processos de transferência de calor. Por fim, análises de CFD serão apresentadas para demonstrar sua característica qualitativa para compreender o comportamento do aquecimento do combustível. Este último tópico será restrito ao conceito de galeria de combustível com aquecedor axial, que é o tipo de sistema de maior domínio dos autores.

\section{O PROPÓSITO DO AQUECIMENTO DE COMBUSTÍVEL}

As duas principais propriedades do combustível envolvidas para a qualidade da partida a frio de motores são a pressão de vapor e o ponto de fulgor. A primeira propriedade está relacionada à vaporização do combustível. Quanto maior a pressão de vapor a temperatura ambiente, mais facilmente o combustível irá vaporizar. Já o ponto de fulgor significa a temperatura a partir da qual o vapor de combustível consegue formar uma atmosfera passível de combustão, que ocorreria com a presença de uma fonte de ignição. Abaixo desta temperatura não ocorre a queima do combustível.

Como apresentado na Tabela 1, as propriedades do etanol não favorecem a partida a frio do motor quando comparadas à gasolina. $\mathrm{O}$ etanol apresenta tanto pressão de vapor bastante 
baixa quanto ponto de fulgor bastante elevado. A gasolina, por outro lado, apresenta as mesmas características bastante favoráveis para a partida a frio. $\mathrm{O}$ seu ponto de fulgor, por exemplo, está bastante abaixo da temperatura ambiente no Brasil, logo este combustível sempre dará condições ao motor partir.

Ao aquecer o etanol, eleva-se sua pressão de vapor, conforme mostra a Figura $1 \mathrm{com}$ a curva de pressão de vapor do etanol obtida pela Expansão de Pitzer [6]. Com a pressão de vapor mais alta, o etanol terá melhor atomização após injeção na câmara de combustão e sua ignição será favorecida. Considerando ainda que a linha de combustível poderá estar pressurizada (tipicamente próximo de 5 bar absoluto para motores PFI - Port Fuel Injection), é possível elevar ainda mais sua temperatura (para aproximadamente $120{ }^{\circ} \mathrm{C}$ ). Isto melhora significativamente a qualidade da partida a frio com etanol e permite que esta seja realizada a temperaturas bem menores que seu ponto de fulgor, já que o etanol será admitido com temperatura acima deste ponto.

Como já dito, o tempo de aquecimento é um parâmetro bastante importante para projetos de sistemas de partida a frio com etanol. Este é um dos principais requisitos das montadoras para evitar insatisfação do usuário final devido à espera pelo fim do processo de aquecimento do combustível. Portanto, não importa apenas que ocorra o processo de aquecimento, mas este deve ser realizado da forma mais rápida possível.

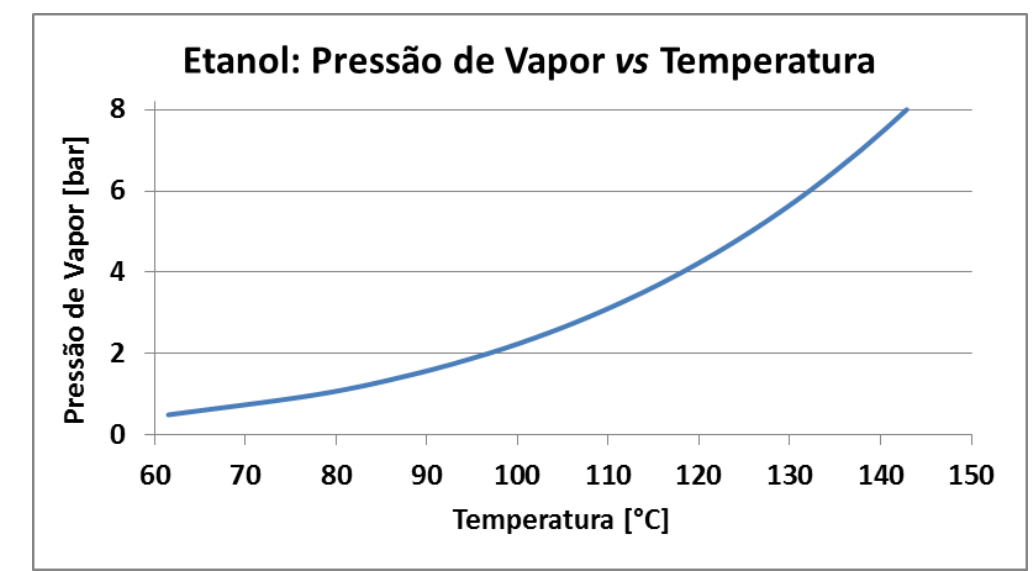

Figura 1: Pressão de vapor do etanol em relação à temperatura

Obviamente, estes componentes também devem trabalhar dentro de uma condição segura ao usuário final. Como se sabe, a tríade combustível-oxigênio-ignição causa combustão, que, se não for controlada, pode causar graves acidentes. Este risco existe uma vez que o sistema conta com a presença de uma fonte de calor. Caso não haja um controle e um projeto seguro para esta fonte de calor, tem-se o risco de incêndio do veículo, que é o pior tipo de falha vindo de uma linha de combustível. Para informação, a Tabela 1 apresenta a temperatura de autoignição do etanol e da gasolina, que significa a menor temperatura que o combustível espontaneamente causa sua própria ignição sem a necessidade de uma fonte externa de ignição.

Por fim, é importante conhecer as etapas da partida a frio com aquecimento de combustível. A Figura 2 mostra de forma ilustrativa estas etapas, que começa com o acionamento do sistema (wake-up), período de aquecimento, partida do motor e manutenção do aquecimento até a temperatura do motor entrar em regime permanente (warm-up). Os pontos P0, P1, P2 e P3 da figura auxiliarão em discussões futuras. 
O início do aquecimento se dá por algum sinal recebido pela unidade de controle do motor (por exemplo, abertura da porta do veículo ou acionamento do pedal de freio) que sinaliza a partida iminente do motor. Observe que os pontos indicados na Figura 2 estão relacionados aos momentos da partida do motor, o que significa que são momentos do combustível quando ele pode estar dentro da galeria de combustível ou após sua injeção na câmara de combustão (vide observação na própria figura).

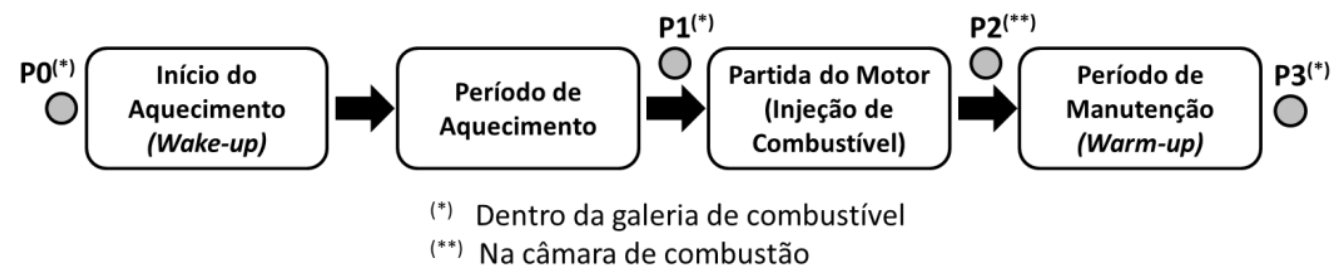

Figura 2: Etapas do aquecimento de combustível para partida a frio

\section{CONSIDERAÇÕES EM TERMODINÂMICA}

Para o andamento desta discussão, as Figuras 2 e 3 serão referenciadas. Os pontos com mesma identificação em ambas as figuras correspondem à mesma etapa de aquecimento. Os conceitos de termodinâmica que devem ser considerados no sistema de partida a frio podem ser divididos em basicamente três grupos: o aquecimento do combustível, a injeção após aquecimento (partida do motor) e período de warm-up.

A Figura 3 apresenta duas condições diferentes: uma com e outra sem a ocorrência de flash boiling na injeção do combustível aquecido (Figuras $3 a$ e $3 b$, respectivamente). Os pontos referenciados nas duas figuras com a mesma numeração correspondem ao mesmo momento do aquecimento. Apenas para diferenciação, o caso sem flash boiling está identificado com um apóstrofo após a identificação do ponto. No entanto, para melhor discussão das etapas, apenas a identificação simplificada será mencionada, sem necessariamente indicar a presença ou não deste fenômeno.

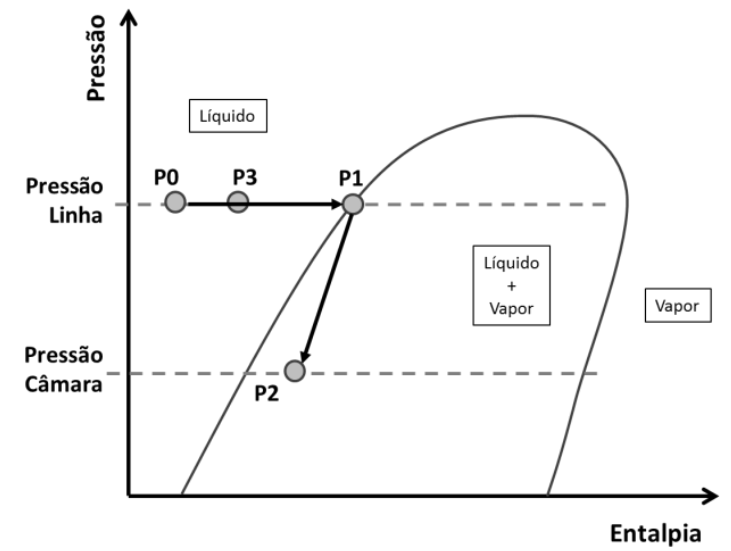

(a)

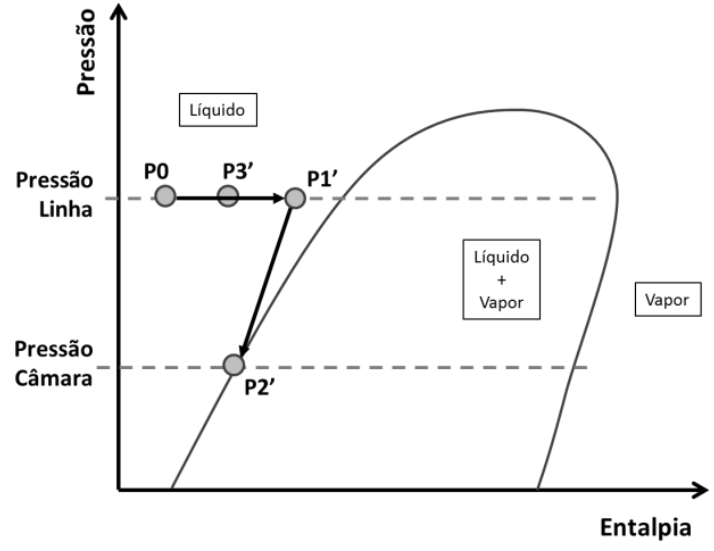

(b)

Figura 3: Etapas do aquecimento em um Diagrama Pressão-Entalpia. (a) Caso com flash boiling. (b) Caso sem flash boiling. 


\section{AQUECIMENTO DO COMBUSTÍVEL (DE PO A P1)}

Este período de aquecimento consiste em um simples aumento de entalpia do combustível na mesma pressão, conforme mostra na Figura 3 a etapa do ponto P0 ao ponto P1. Este processo pode ser modelado pela $E q$. 1 , onde $\dot{Q}_{P 0 \rightarrow P 1}$ é a potência do aquecimento, $m_{c o m b}$ a massa de combustível a ser aquecida, $h$ a entalpia específica, $t$ o tempo, $\rho_{c o m b}$ a densidade (ou massa específica) do combustível, $V_{G C}$ o volume de combustível na galeria de combustível, $c_{p_{c o m b}} \mathrm{o}$ calor específico do combustível, $T_{P 0}$ e $T_{P 1}$ as temperaturas dos pontos P0 e P1, respectivamente, e $\Delta t$ o tempo de aquecimento de combustível (do ponto P0 ao P1).

$$
\dot{Q}_{P 0 \rightarrow P 1}=m_{c o m b} \frac{d h}{d t}=\rho_{c o m b} V_{G C} c_{p_{c o m b}} \frac{\left(T_{P 1}-T_{P 0}\right)}{\Delta t}
$$

Em outras palavras, dado o combustível (logo se tem sua densidade e calor específico), o volume a ser aquecido (por exemplo, o volume da galeria de combustível) e a diferença da temperatura-objetivo (ponto P1) e da temperatura inicial do combustível (ponto P0), é possível estimar a ordem de grandeza da potência da fonte de aquecimento. Para um cálculo mais preciso, basta adicionar o calor dirigido ao aquecimento dos corpos adjacentes, como a galeria e os injetores de combustível.

\section{PARTIDA DO MOTOR (DE P1 A P2)}

Quando ocorre a partida do motor, tem-se a injeção do combustível previamente aquecido, o que significa a queda rápida da pressão do combustível (da pressão da linha de combustível para a pressão da câmara de combustão). Este processo idealmente é isentrópico. Porém, no caso real, há uma leve diminuição de entropia ao passar pelo injetor de combustível e até chegar à câmara de combustão.

Há um caso importante a se considerar nesta etapa: flash boiling. Este fenômeno consiste na vaporização e "estouro" do vapor em uma queda brusca de pressão quando este está com entalpia acima da saturação para a pressão inferior (da câmara de combustão). Como visto na Figura 3, o caso com flash boiling mostra o ponto $\mathrm{P} 2 \mathrm{em}$ uma região com título de vapor. Este vapor formado pode prejudicar a penetração da injeção de combustível, pois ocorre um "estouro" que descaracteriza o jato. Um trabalho interessante sobre o assunto foi feito por Huang et al [7] sobre influência da temperatura do combustível (etanol e gasolina) antes da injeção na existência do flash boiling. Eles observaram que a injeção com temperatura levemente superior (4 K) à saturação não causa flash boiling.

Desta forma, o aquecimento do combustível deve ser realizado de forma que o ponto P2 se encontre no máximo na linha de saturação para a pressão da câmara (como o ponto P2' da Figura 3b). Aquecer o combustível na pressão da linha até a saturação (ponto P1, como na Figura 3a) aumenta o risco de prejudicar a injeção de combustível por conta do flash boiling, comprometendo significativamente a partida do motor.

\section{PERÍODO DE MANUTENÇÃO (DE P2 A P3)}

Após a partida do motor, ainda é necessário manter o aquecimento do combustível de forma a sustentar o funcionamento do motor e garantir boa dirigibilidade do veículo pós-partida. 
Porém, como é apenas uma manutenção do aquecimento, é interessante aquecer o combustível o mínimo suficiente para atender os objetivos e expectativas (como dito, boa dirigibilidade e, se for o caso, diminuição de emissões de combustível, tal como estudado por Sales e Sodré [8]). Desta forma, continua-se evitando flash boiling após a injeção de combustível.

Este processo também pode ser estimado como mostra a $E q$. 2, onde $\dot{Q}_{P 3}$ é a potência de aquecimento na manutenção, $\dot{m}_{c o m b}$ a vazão de combustível e $T_{P 3}$ a temperatura do ponto P3. Com esta equação pode-se calcular aproximadamente o controle PWM (Pulse Width Modulation) a ser utilizado, pois é esperado que a potência utilizada neste momento seja menor do que no período de aquecimento pré-partida.

$$
\dot{Q}_{P 3}=\dot{m}_{c o m b} c_{p_{c o m b}}\left(T_{P 3}-T_{P 0}\right)
$$

\section{CONSIDERAÇÕES EM TRANSFERÊNCIA DE CALOR}

O aquecimento de combustível envolve os principais fenômenos de transferência de calor: condução, convecção e ebulição. Radiação e transferência de massa também estão presentes, porém possuem pouca relevância para projetos de sistemas de aquecimento de combustível. Uma descrição geral destes fenômenos é encontrada em livros-textos conhecidos, como Incropera et al [9], e uma revisão mais detalhada em livros como o Handbook of Heat Transfer [10].

O fenômeno de condução térmica, que consiste na transferência de calor em escala microscópica internamente em um corpo, está fortemente presente nos componentes constituintes do sistema de aquecimento. Sua análise é essencial para calcular as temperaturas máximas de trabalho dos componentes. Desta forma se pode selecionar o material com melhor custo-benefício, porém ainda apropriado para o trabalho.

Os fenômenos de convecção e ebulição estão presentes no fluido em todas as fases do aquecimento de combustível apresentadas na Figura 2. Também estão tanto relacionados à fluidodinâmica do combustível quanto ao resfriamento da fonte de aquecimento.

\section{CONVECÇÃ̃}

Convecção, um dos principais fenômenos de transferência de calor presentes na natureza, consiste na difusão de calor em conjunto com a movimentação de um fluido (advecção). Este movimento pode ser motivado por um empuxo devido a um gradiente de temperatura que causa diferença de densidade (convecção natural) ou por uma fonte externa (convecção forçada). Nos sistemas de aquecimento de combustível, a convecção natural está presente no período pré-partida do motor (do ponto P0 ao P1, da Figura 2), enquanto que a convecção forçada, causada pela abertura dos injetores de combustível, se encontra no período de partida e pós-partida (do ponto P1 ao P3 da mesma figura). A análise deste fenômeno no projeto do sistema de aquecimento é mais conceitual do que matemática. Um diagnóstico qualitativo destes fenômenos pode ser realizado com Fluidodinâmica Computacional (CFD), que será tratado posteriormente. 
Da convecção natural, a primeira consideração a ser feita, apesar de óbvia, é a ascensão do fluido quente e a descida do fluido frio. Desta forma, para otimizar o sistema e conseguir o melhor desempenho da partida do motor, é interessante coletar o fluido quente na região superior para a injeção. Coletar em uma região com fluido frio pode dificultar bastante a partida do motor para temperaturas bastante baixas.

Já da convecção forçada, pouco se consegue avaliar devido a diversos fenômenos secundários e inerentes ao processo que criam forte aleatoriedade ao escoamento, como mudança de fase, escoamento bifásico e turbulência. Isto torna inclusive a avaliação pouco intuitiva, demandando maior esforço para experimentos específicos de cada sistema de aquecimento. Por este motivo, este assunto não será abordado no presente trabalho.

\section{EBULIÇÃO}

Ebulição é definida pelo Professor-Emérito Geoffrey Hewitt do Imperial College London no Capítulo 15 do Handbook of Heat Transfer [10] como "um processo de adição de calor a um líquido de forma que ocorra geração de vapor". Este fenômeno é um dos principais ramos de pesquisa em transferência de calor devido aos seus altos coeficientes de troca de calor e alta complexidade. Sua característica aleatória e brusca de formação de vapor torna difícil uma compreensão analítica e generalizada do processo, apesar de haver bastante avanço em seus estudos nas últimas décadas.

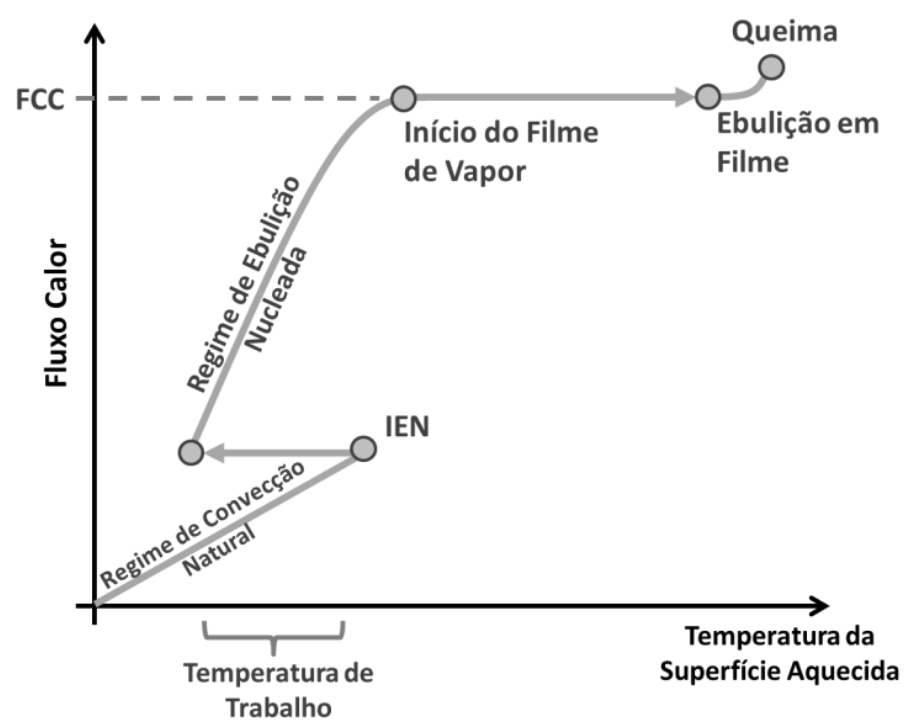

Figura 4: Curva de ebulição ilustrativa com pontos críticos e regime de ebulição nucleada

A Figura 4 apresenta ilustrativamente uma curva de ebulição a ser considerada em projetos de sistemas de aquecimento de combustível. Como se pode ver, com o aumento do fluxo de calor (potência dividida pela área de troca de calor) pela fonte aquecedora, aumenta-se a temperatura de sua superfície. Isto ocorre inicialmente em um regime de convecção natural. Quando o fluxo de calor atinge um determinado valor, tem-se o Início da Ebulição Nucleada (IEN), que consiste no início de formação de bolhas isoladas pela superfície da fonte aquecedora. Isto causa um rápido resfriamento da superfície, já que a ebulição consegue trocar calor mais eficientemente do que convecção. Este regime se mantem com o aumento do fluxo de calor (que, consequentemente, aumenta a quantidade de vapor formado) até um 
ponto conhecido com Fluxo Crítico de Calor (FCC). Neste momento, começa a formação de um filme de vapor na superfície aquecedora que atua como um "isolante térmico", causando um aumento repentino da superfície de troca de calor e, consequentemente, sua queima. A Figura 5 apresenta fotos de algumas situações apresentadas na Figura 4 em ensaio com fio aquecido.
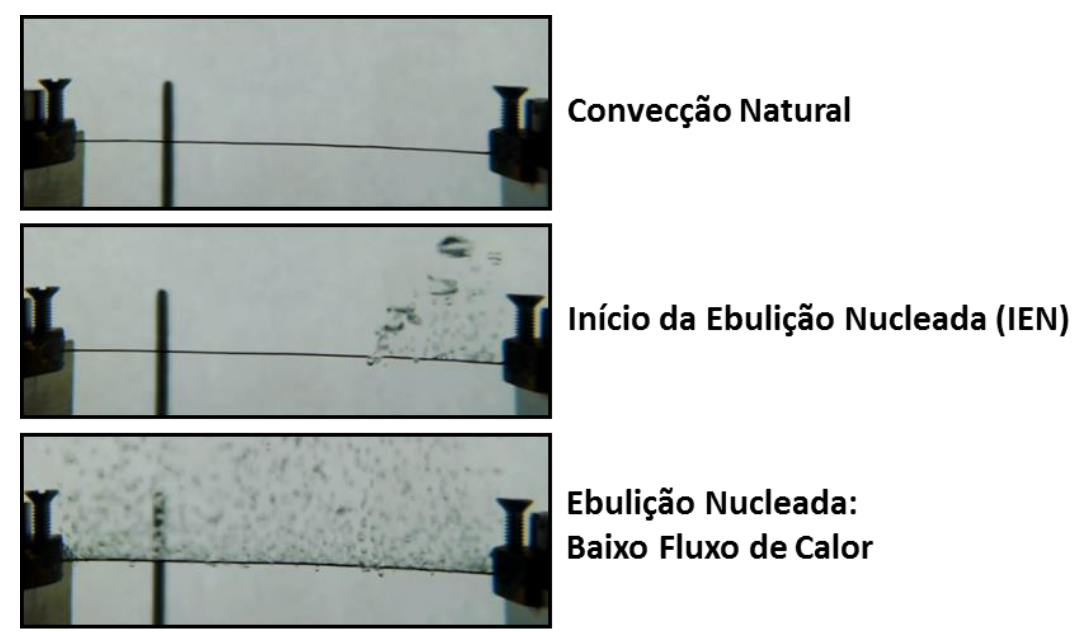

Ebulição Nucleada:

Baixo Fluxo de Calor

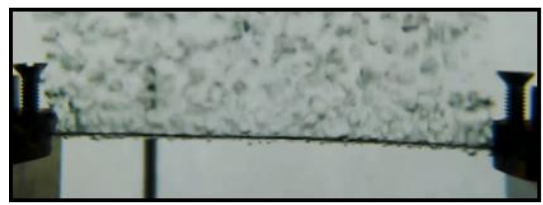

Ebulição Nucleada:

Alto Fluxo de Calor

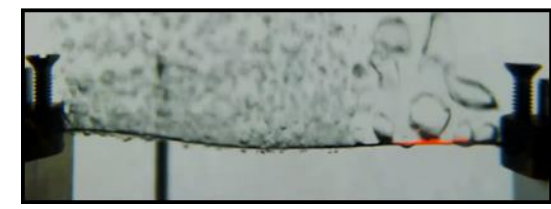

Fluxo Crítico de Calor (FCC)

Figura 5: Momentos e condições encontradas no fenômeno de ebulição nucleada (ensaio com etanol anidro)

No sistema de aquecimento de combustível, a fonte aquecedora deve trabalhar, no pior caso, dentro do regime de ebulição nucleada e o mais afastado possível do FCC. A formação do filme de vapor aumenta significativamente a temperatura da superfície e pode danificar os componentes do sistema, como galeria e injetor de combustível. Um exemplo de afastar o trabalho do FCC é, por exemplo, utilização de PWM no controle da potência do aquecedor.

O FCC pode ser estimado com algumas correlações existentes na literatura, porém resultados precisos somente são possíveis conseguir experimentalmente. Além disto, o FCC é diferente para cada fluido (ou mistura de fluidos) e é afetado por vários parâmetros, como pressão, temperatura do fluido, dimensão da superfície, confinamento, entre outros.

Para visualizar a diferença da ebulição em etanol anidro e em gasolina pura, a Figura 6 apresenta curvas experimentais de ensaio de ebulição para ambos os fluidos a 1 bar de pressão absoluta na temperatura de saturação (aproximadamente $78,0{ }^{\circ} \mathrm{C}$ para o etanol e $64,6{ }^{\circ} \mathrm{C}$ para a gasolina). Como se pode ver, o etanol transfere calor melhor do que a gasolina e tem FCC mais elevado na pressão de 1 bar. Isto significa que no projeto da fonte aquecedora a gasolina serve como caso crítico quando comparada ao etanol, pois seu FCC é menor e a temperatura da superfície mais alta. 


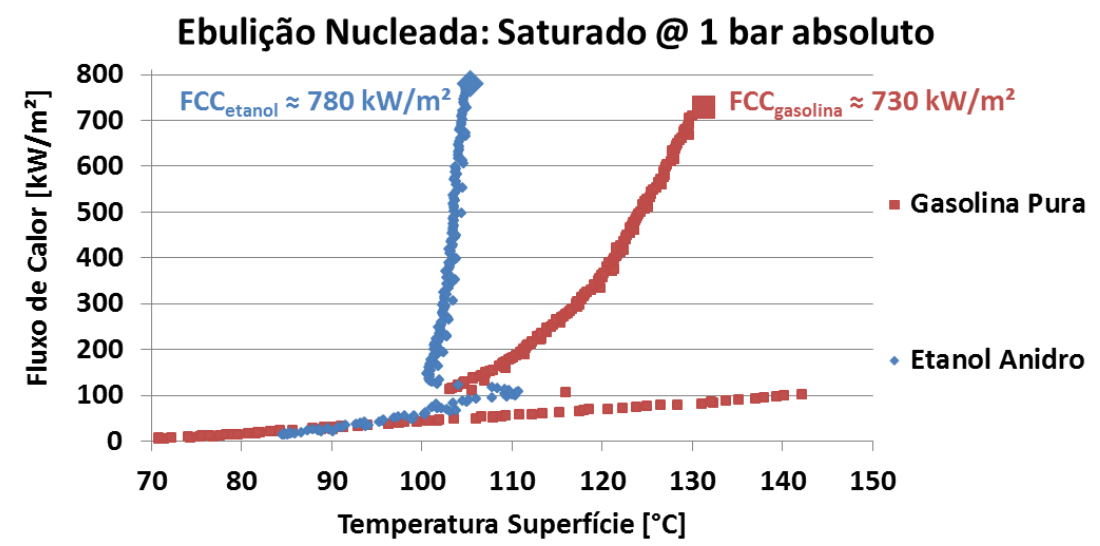

Figura 6: Curvas experimentais de ensaio de ebulição nucleada para etanol anidro e gasolina pura

Apesar da linha de combustível trabalhar com pressão acima da atmosférica, este exemplo serve para ilustrar a diferença de transferência de calor entre os dois combustíveis. Park et al [11] estudaram FCC em ebulição transiente com etanol anidro a diversas pressões. Em seu trabalho, pode-se ver que, para etanol a 4,94 bar de pressão, a temperatura da superfície em regime de ebulição nucleada está entre $130{ }^{\circ} \mathrm{C}$ e $140{ }^{\circ} \mathrm{C}$ e o FCC aproximadamente 1000 $\mathrm{kW} / \mathrm{m}^{2}$. Estes parâmetros já fornecem uma ordem de grandeza das condições de trabalho da fonte aquecedora em um sistema de aquecimento de combustível.

Poder-se-ia discutir diversos outros assuntos de ebulição que devem ser considerados no projeto de um sistema de aquecimento de combustível, como a mistura dos combustíveis, características geométricas, confinamento, etc. Porém, o objetivo desta seção específica para ebulição é apresentar superficialmente o fenômeno e suas principais características, além de uma breve demonstração de resultados com combustíveis utilizados no mercado brasileiro.

\section{FLUIDODINÂMICA COMPUTACIONAL COMO FERRAMENTA DE PROJETO}

$\mathrm{Na}$ engenharia, as simulações computacionais são importantes ferramentas de desenvolvimento de produtos e processos para predizerem o comportamento destes quando sujeitos a determinadas condições de contorno. Os cálculos vêm ganhando força por uma série de razões, nas quais podemos citar algumas delas:

- Necessidade de predição para diminuir os altos riscos técnicos e econômicos envolvidos no desenvolvimento de produto;

- Uma vez o componente validado em cálculos computacionais, haverá menos testes de validação e de verificação de desempenho (que possuem elevado custo, principalmente quando os ensaios são destrutíveis); 
- Possibilidade de variação de parâmetros para avaliação de diferentes cenários, assim como a obtenção de um maior número de resultados extraídos de uma simulação quando comparados a um experimento físico.

- Alta capacidade de trabalhos de otimização em aspectos ligados ao processo de desenvolvimento de produto como: redução dos prazos de desenvolvimento, pressões competitivas para diferenciar os produtos com melhor qualidade/confiabilidade, demanda dos clientes por produtos de menor custo, entre outros [12].

Cálculos CFD (do inglês Computational Fluid Dynamics) são bastante utilizados na predição de fenômenos físicos ou físico-químicos que ocorrem em escoamento de fluido. Estudos mostram que empresas que utilizam CFD durante o projeto são $21 \%$ mais propensos a cumprir o cronograma do que aqueles que não utilizam estas ferramentas, tornando, portanto, o seu uso uma parte importante do ROI (Return of Investment) do projeto [12]. Logo, esta ferramenta deve ser ativamente utilizada durante o desenvolvimento de componentes de sistemas de aquecimento de combustível, tendo em vista a importância das simulações CFD e a complexidade e quantidade de fenômenos físicos envolvidos.

Conforme dito na introdução deste trabalho, o caso proposto para apresentar a qualidade de resultados de simulação CFD será o de galeria de combustível com aquecedores axiais, pois este é o conceito de maior familiaridade dos autores. É certo que o discutido aqui pode valer para outros conceitos de sistema de partida a frio, porém estes não serão debatidos.

No ciclo de desenvolvimento de galerias de combustível com aquecedores axiais, as simulações transientes reproduzem as fases P0, P1 e P3 (vide Figura 2) da partida a frio a fim de predizerem o comportamento do aquecimento e escoamento do fluido. Também se analisa o aquecimento dos componentes do sistema, como a galeria de combustível. Os resultados auxiliam o engenheiro do produto na tomada de decisão para as alterações de design que conduzam ao melhor desempenho possível quando sujeito às condições de contorno impostas.

As evoluções dos modelos matemáticos e capacidade computacional (hardware mais potentes e capazes) permitem, nos dias de hoje, representar matematicamente os fenômenos físicos presentes em um sistema de aquecimento de combustível com alto nível de fidelidade. Estas mesmas evoluções de capacidade computacional incentivam estudos teóricos e experimentais em áreas como, por exemplo, turbulência e ebulição nucleada.

Porém, apesar das evoluções recentes atingidas, ainda é muito caro (custo de tempo e computacional) utilizar altos níveis de fidelidade durante um ciclo de desenvolvimento de produto. Por este motivo as simulações voltadas para o projeto de galeria de combustível com aquecedor axial são simplificadas. Apesar das simplificações apresentadas na Tabela 2, a simulação CFD com transferência de calor se mostra uma excelente ferramenta de avaliação de desempenho durante o seu desenvolvimento.

Abaixo na Figura 7 são mostrados resultados referentes à evolução da temperatura do etanol em função do tempo dentro de uma galeria de combustível das fases P0, P1 e P3 da partida a frio de um motor. Ao se comparar resultados experimentais em veículo (linhas pontilhadas) e resultados de simulação CFD (linhas contínuas), é possível observar que, qualitativamente, o comportamento das curvas de aquecimento medido e simulado é bastante semelhante, apesar dos valores absolutos não serem correlatos. 
Tabela 2: Fenômenos físicos presentes em sistemas de aquecimento de combustível e simplificações adotadas para simulações $C F D$

\begin{tabular}{|c|c|}
\hline $\begin{array}{c}\text { Fenômenos físicos presentes no sistema } \\
\text { de aquecimento de combustível }\end{array}$ & $\begin{array}{c}\text { Fenômenos físicos aplicados em } \\
\text { simulações do sistema de aquecimento } \\
\text { de combustível }\end{array}$ \\
\hline $\begin{array}{c}\text { Fluido com comportamento BIFÁSICO } \\
\text { (etanol líquido e vapor) }\end{array}$ & $\begin{array}{c}\text { Fluido com comportamento MONOFÁSICO } \\
\text { (apenas etanol líquido) }\end{array}$ \\
\hline \multicolumn{2}{|c|}{ Transferência de calor por CONVECÇÃO } \\
\hline Transferência de calor por CONDUÇÃO \\
\hline COM transferência de calor por RADIAÇÃO & SEM transferência de calor por RADIAÇÃO \\
\hline COM transferência de calor por EBULIÇÃO & SEM transferência de calor por EBULIÇÃO \\
\hline Escoamento de fluido TURBULENTO & Escoamento de fluido LAMINAR \\
\hline $\begin{array}{c}\text { Propriedade dos materiais EM FUNÇÃO DA } \\
\text { TEMPERATURA }\end{array}$ & Propriedade dos materiais CONSTANTES \\
\hline
\end{tabular}

Temperatura do etanol em função do tempo

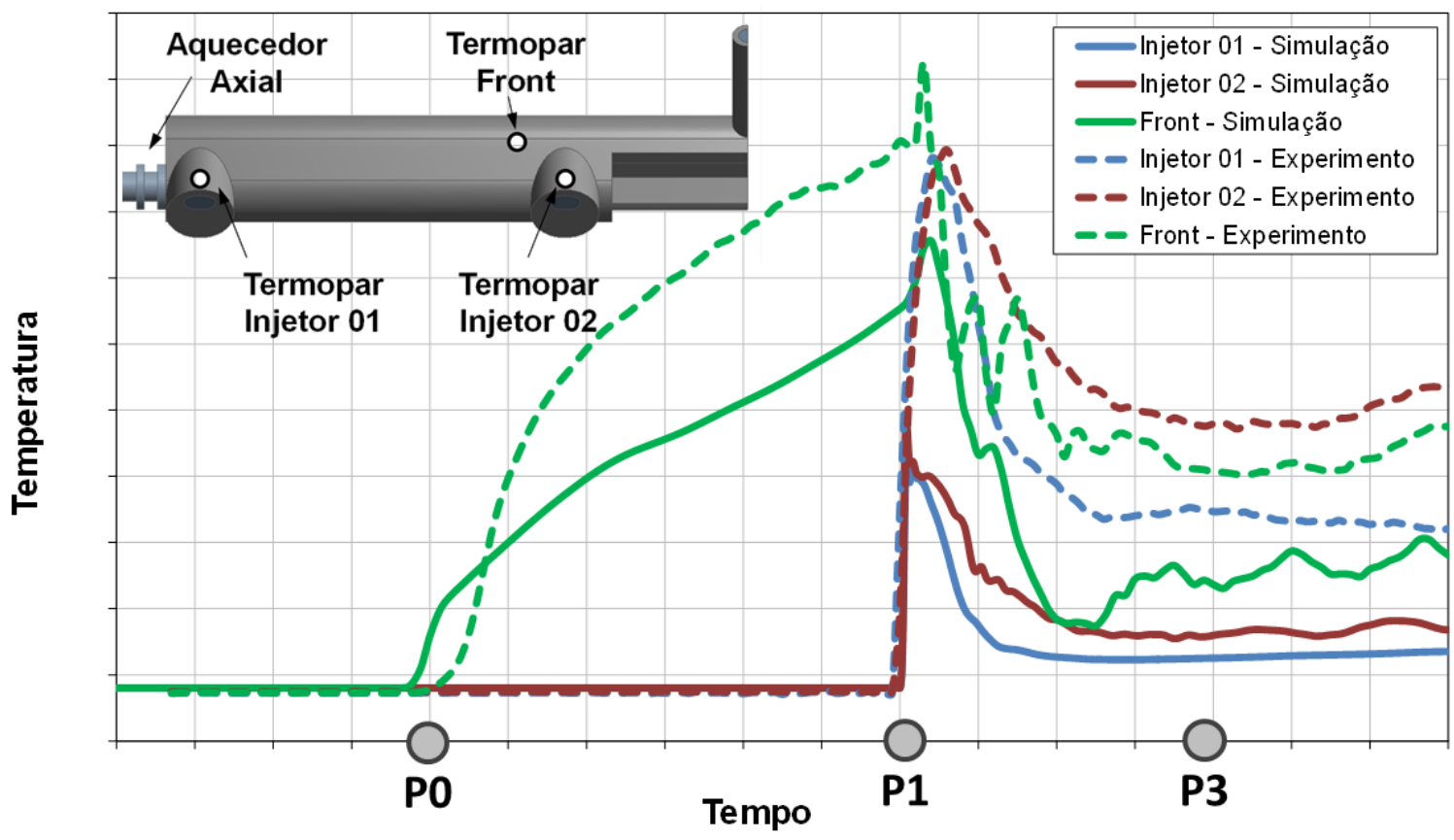

Figura 7: Gráfico comparativo entre resultados de simulação e experimento da temperatura do etanol em galerias de combustível com aquecedores axiais

Esta diferença quantitativa se dá pela simplificação adotada no modelo matemático da simulação CFD apresentada na Tabela 2. Porém, o resultado qualitativo ainda é válido e bastante representativo. Dois exemplos de comparação entre os resultados que podem ser observados: 
- O combustível aquecido tem uma rápida subida de temperatura no início (ponto P0) e depois ocorre mais lentamente. Com o início da injeção para a partida do motor (ponto P1), há um curto pico de temperatura seguido por uma queda, com presença de oscilações no caminho. Por fim, a temperatura tende à um valor estável.

- A todo o momento desde o início da partida do motor (ponto P1), o combustível passando pelo injetor 02 é mais quente do que o que flui pelo injetor 01. Porém, no momento da partida, os picos do combustível passando por ambos os injetores atingem temperaturas bastante próximas.

Como se pode ver, com um cálculo de menor custo e mais simplificado, em conjunto com o conhecimento dos fenômenos inerentes ao sistema de aquecimento de combustível, o engenheiro de produto terá ferramentas suficientes para analisar a qualidade do projeto em desenvolvimento. Da mesma forma, também é possível buscar uma geometria e condição ótima e, assim, buscar atender o cliente com o melhor produto que possa oferecer.

\section{CONCLUSÃO}

Com o advento dos sistemas de aquecimento de combustível para partida a frio de motores de combustão interna, houve a necessidade do aprendizado dos fenômenos termodinâmicos e de transferência de calor envolvidos nos processos. Esta é a proposta principal do presente trabalho.

Nas considerações em termodinâmica, é possível estimar a potência necessária para promover o aquecimento pré-partida e a manutenção pós-partida. Porém, deve-se ter em mente a ocorrência do flash-boiling no caso de um aquecimento demasiado do combustível, que precisa ser evitado para não comprometer a qualidade da partida do motor.

Na discussão de transferência de calor, foram apresentados com mais detalhes os fenômenos de convecção e de ebulição. O primeiro requer uma análise mais conceitual do que analítica, visto os fenômenos secundários que causam aleatoriedade ao processo. Já a ebulição deve ser tratada com mais precisão para evitar a ocorrência de um superaquecimento da fonte de calor. Resultados experimentais mostram que a gasolina tem menor capacidade de dissipar o calor da superfície aquecida e, por isto, deve ser considerada como caso crítico para projetos de sistemas de aquecimento de combustível.

Por fim, foi debatida a qualidade de simulações CFD para auxiliar projetos destes sistemas. Apesar das dificuldades e desvantagens de reproduzir em simulação todos os fenômenos discutidos no presente trabalho, é possível fazer uma análise simplificada que fornece resultados comportamentais do aquecimento e escoamento do combustível. Para demonstrar esta possibilidade, uma comparação foi feita com resultados experimentais e calculados de um sistema de galeria de combustível com aquecedores axiais, onde se pôde ver forte correlação qualitativa. Esta ferramenta, em conjunto com o conhecimento dos fenômenos previamente discutidos, fornece ao engenheiro de produto informação suficiente para desenvolver e oferecer aos seus clientes o melhor de seu sistema de aquecimento de combustível. 


\section{REFERÊNCIAS}

[1] LEITE, R. C.; CORTEZ, L. A. B.. O Etanol Combustível no Brasil. Disponível em http://sistemas.mre.gov.br/kitweb/datafiles/NovaDelhi/pt-br/file/Biocombustiveis_04etanolcombustivelnobrasil.pdf. Acesso em: 07 de Maio de 2016.

[2] Automotive Business. Tecnologia Bicombustível Completa Dez Anos. Disponível em http://www.automotivebusiness.com.br/noticia/16605/tecnologia-bicombustivel-completadez-anos. Acesso em: 07 de Maio de 2016.

[3] U.S. Coast Guard. Chemical Hazard Response Information System (CHRIS) Hazardous Chemical Data. Disponível em: http://www.uscg.mil/directives/cim/1600016999/CIM_16465_12C.pdf. Acesso em: 26 de Maio de 2016.

[4] FAJGENBAUM, R. Influência da Temperatura do Combustível nos Parâmetros de Atomização de um Atomizador Utilizado em Bicos Injetores Automotivos. Tese de Mestrado, Faculdade de Engenharia Mecânica, UNICAMP. 2013.

[5] NIGRA JÚNIOR, E. L. P. Análise da influência da temperatura e da pressão de injeção e do tipo de combustível nas caracteristicas do spray de injetores PFI. Tese de Mestrado, Faculdade de Engenharia Mecânica, UNICAMP. 2016.

[6] POLING, B. E.; PRAUSNitZ, J. M.; O’CONNELL, J. P.. The Properties of Gases and

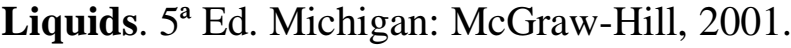

[7] HUANG, Y.; HUANG, S.; HUANG, R.; HONG, G.. Spray and Evaporation Characteristics of Ethanol and Gasoline Direct Injection in Non-Evaporating, Transition and Flash-Boiling Conditions. Energy Conversion and Management, Vol. 108, pp. 68-77, 2016. [8] SALES, L. C. M.; SODRÉ, J. R.. Cold Start Emissions of an Ethanol-Fuelled Engine with Heated Intake Air and Fuel. Fuel, Vol. 95, pp. 122-125, 2012.

[9] INCROPERA, F. P.; DEWITT, D. P.; BERGMAN, T. L.; LAVINE, A. S.. Fundamentals of Heat and Mass Transfer. $6^{a}$ Ed, John Wiley \& Sons, 2006.

[10] ROHSENOW, W. M.; HARTNETT, J. P.; CHO, Y. I.. Handbook of Heat Transfer. $3^{\text {a }}$ Ed, McGraw-Hill, 1998.

[11] PARK, J.; FUKUDA, K.; LIU, Q.. Transient CHF Phenomena Due to Exponentially Increasing Heat Inputs. Nuclear Engineering and Technology, Vol. 41, pp. 1205-1214, 2009.

[12] BOUCHER, M. The ROI of the Concurrent Design with CFD. Aberdeen Group, Inc. 2011. 